\title{
Oil Body-Bound Oleosin-rhFGF-10: A Novel Drug Delivery System that Improves Skin Penetration to Accelerate Wound Healing and Hair Growth in Mice
}

\author{
Wenqing Li ${ }^{1,+} \mathbb{D}$, Jing Yang ${ }^{1,+}$, Jingbo Cai ${ }^{1}$, Hongyu Wang ${ }^{1}$, Haishan Tian ${ }^{2}$, Jian Huang ${ }^{1}$, \\ Weidong Qiang ${ }^{1}$, Linbo Zhang ${ }^{1}$, Haiyan $\mathrm{Li}^{1, *}$, Xiaokun $\mathrm{Li}^{2, *}$ and Chao Jiang ${ }^{2,3, *}$ \\ 1 College of Life Sciences, Engineering Research Center of the Chinese Ministry of Education for Bioreactor \\ and Pharmaceutical Development, Jilin Agricultural University, Changchun 130118, China; \\ liwenqingshiwo@163.com (W.L.); yangjing5122010@163.com (J.Y.); cjb1045@163.com (J.C.); \\ ccwhy@126.com (H.W.); hnjianhuang@yeah.net (J.H.); qiangweidong616@163.com (W.Q.); \\ cczlb@126.com (L.Z.) \\ 2 Wenzhou Biomedical Innovation Center, Wenzhou University, Wenzhou 325035, China; \\ tianhaishan6418@163.com \\ 3 College of Life and Environmental Sciences, Wenzhou University, Wenzhou 325035, China \\ * Correspondence: hyli99@163.com (H.L.); xiaokunli@163.net (X.L.); chaojiang10@163.com (C.J.); \\ Tel.: +86-431-8453-2885 (H.L.); +86-431-8453-3427 (X.L.); +86-431-8453-3428 (C.J.); \\ Fax: +86-431-8453-2885 (H.L.); +86-431-8453-3347 (X.L.); +86-431-8453-3347 (C.J.) \\ + These authors contributed equally to this work.
}

Received: 25 September 2017; Accepted: 15 October 2017; Published: 18 October 2017

\begin{abstract}
Recombinant human fibroblast growth factor 10 (rhFGF-10) is frequently used to treat patients with skin injuries. It can also promote hair growth. However, the effective application of rhFGF-10 is limited because of its poor stability and transdermal absorption. In this study, polymerase chain reaction (PCR) and Southern blotting were used to identify transgenic safflowers carrying a gene encoding an oleosin-rhFGF-10 fusion protein. The size and structural integrity of oleosin-rhFGF-10 in oil bodies extracted from transgenic safflower seeds was characterized by polyacrylamide gel electrophoresis and western blotting. Oil body extracts containing oleosin-rhFGF-10 were topically applied to mouse skin. The absorption of oleosin-rhFGF-10 was studied by immunohistochemistry. Its efficiency in promoting wound healing and hair regeneration were evaluated in full thickness wounds and hair growth assays. We identified a safflower line that carried the transgene and expressed a $45 \mathrm{kDa}$ oleosin-rhFGF-10 protein. Oil body-bound oleosin-rhFGF-10 was absorbed by the skin with higher efficiency and speed compared with prokaryotically-expressed rhFGF-10. Oleosin-rhFGF-10 also enhanced wound closure and promoted hair growth better than rhFGF-10. The application of oleosin-rhFGF-10 in oil bodies promoted its delivery through the skin, providing a basis for improved therapeutic effects in enhancing wound healing and hair growth.
\end{abstract}

Keywords: oil body; oleosin-rhFGF-10; skin penetration; wound healing; hair growth

\section{Introduction}

Fibroblast growth factor 10 (FGF-10), also referred to as keratinocyte growth factor 2 (KGF-2), is a $24 \mathrm{kDa}$ member of the fibroblast growth factor family and is composed of 208 amino acids [1]. Recombinant human FGF-10 (rhFGF-10) can enhance the proliferation of epidermal cells, and thereby promote the healing of injured skin [2]. It is frequently used to treat patients with mechanical injuries, burns and scalds of the skin, and it reduces scarring after healing [3]. Meanwhile, FGF-10 is necessary for hair growth, and may induce hair growth through activation of fibroblast growth factor receptor 2 [4], and also activation of the $\beta$-catenin and sonic hedgehog signaling pathways [5]. 
Although rhFGF-10 has been successful expressed in vitro [6,7], clinical application is limited because of its short half-life, poor thermal stability and low expression level. The heparin-binding domain of fibrin binds growth factors and can enhance the stability of FGF-10 and promote wound healing [8]. Polyethylene glycol modification of rhFGF-10 can decrease its immunogenic activity and improve its biostability, but its relative mitogenic activity is also reduced [9]. The oil body protein system has been utilized successfully to produce a variety of biologically active proteins in plant seeds, such as hirudin, insulin, epidermal growth factor and hyaluronidase [10-14]. In the process of seed maturation, $95 \%$ of the water content is lost [15], resulting in decreased activity of proteolytic enzymes, which improves the long-term storage of proteins and the effects of protein drugs. In light of the effects of FGF-10 in promoting cell division, proliferation, differentiation and migration, we have used the oil body protein system to produce an rhFGF-10 protein for delivery to skin. We used genetic engineering techniques to produce rhFGF-10 conjugated with the oil body-bound protein, oleosin. This is a novel approach to delivering drugs to skin, as the oil body not only enhances the stability of the recombinant protein, but also increases its skin penetration and subsequent effects on wound healing and hair growth.

\section{Results}

\subsection{Stable Integration of the Oleosin-rhFGF-10 Gene in Safflowers}

A polymerase chain reaction (PCR) assay revealed that two lines of transgenic safflower carried the oleosin-rhFGF-10 gene (Figure 1a). A PCR product of approximately $500 \mathrm{bp}$ was amplified using rhFGF-10-specific primers, which was the expected size. A Southern blot analysis was performed to confirm that the oleosin-rhFGF-10 gene had integrated into the safflower genome of these lines, and to determine the copy number. Only one transformed line showed a hybridization signal, and the oleosin-rhFGF-10 copy number was one (Figure 1b). This transgenic safflower line was used for large-scale propagation, to provide experimental material for the rest of the study.
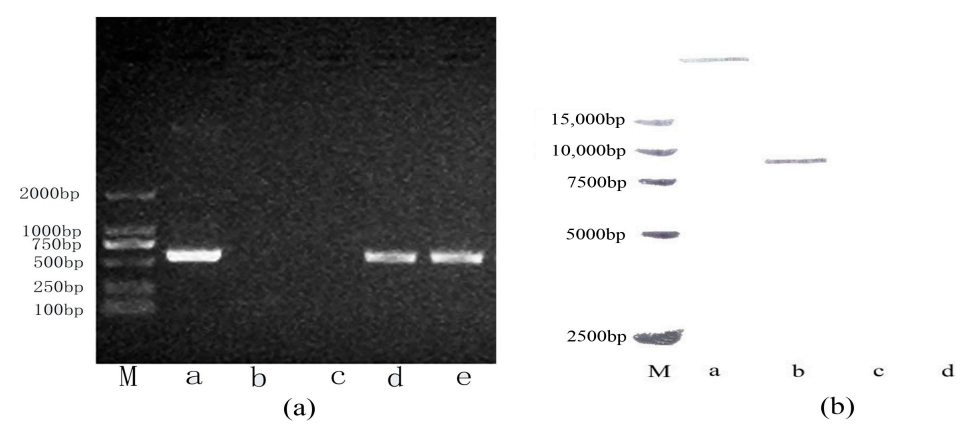

Figure 1. Integration of the oleosin-rhFGF-10 gene following safflower transformation. (a) Polymerase chain reactions (PCR) showing that the oleosin-rhFGF-10 gene had been inserted into the genome of transgenic safflowers. Lane $M$, molecular weight standards, lane $a$, positive control; lane $b$, negative control; lane c, blank control; lanes d-e, transgenic safflower lines. The PCR product is approximately $500 \mathrm{bp}$; (b) Southern blot showing a positive hybridization signal only for the positive control, lane a, and one of two transgenic safflower lines, lanes $b-c$. The wild type safflower, lane $d$, was negative. The number of oleosin-rhFGF-10 gene copies in the positive transgenic line was one.

\subsection{Oleosin-rhFGF-10 Protein Analysis}

The expression of oleosin-rhFGF-10 protein was confirmed by sodium dodecyl sulfate polyacrylamide gel electrophoresis and western blotting (Figure 2). The rhFGF-10 protein band was approximately $24 \mathrm{kDa}$ and the oleosin-rhFGF-10 fusion protein band was approximately $45 \mathrm{kDa}$ (Figure 2a). No band around $45 \mathrm{kDa}$ was seen in wild-type (WT) oil body extract. Further western blotting experiments established that these proteins were rhFGF-10 and oleosin-rhFGF-10. The $24 \mathrm{kDa}$ 
and $45 \mathrm{kDa}$ bands stained positively for rhFGF-10 and oleosin-rhFGF-10 fusion protein, respectively (Figure 2b). The WT protein was negative. These results show that the protein of interest was successfully expressed in safflower seeds.

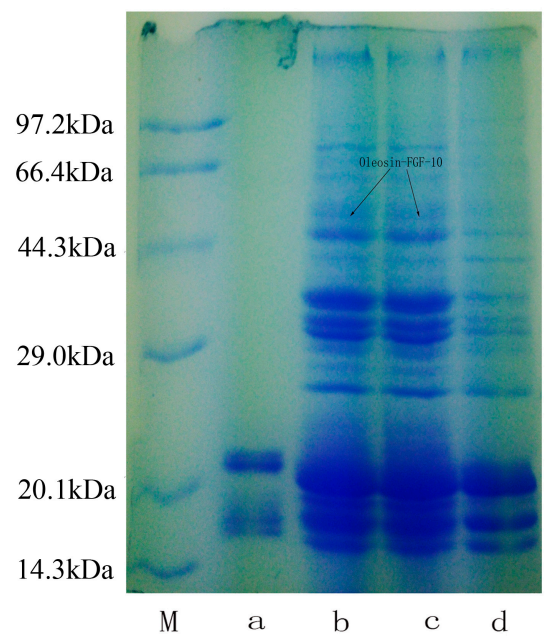

(a)

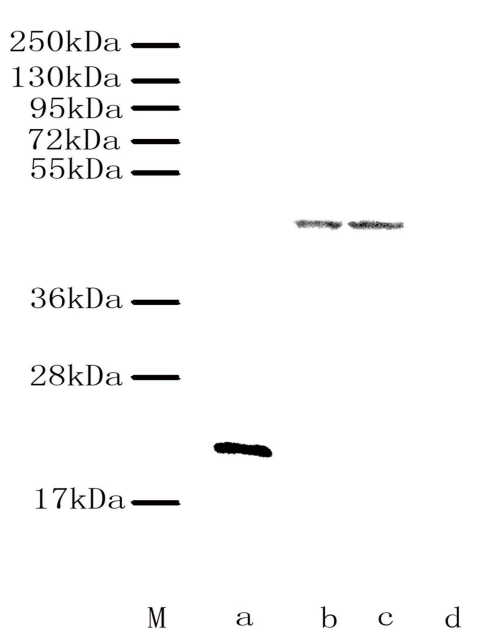

(b)

Figure 2. Protein analysis of oleosin-rhFGF-10. (a) Oil body proteins after $12 \%$ denaturing gel electrophoresis and Coomassie brilliant blue R250 staining. Lane M, molecular weight standards, lane a, rhFGF-10; lanes $b-c$, the same transgenic safflower lines; lane d, wild-type safflowers. Black arrows indicate the protein of interest and its molecular weight of $45 \mathrm{kDa}$; (b) western blot detection of the oleosin-rhFGF-10 protein. Lanes are as for (a).

\subsection{The Ability of Oleosin-rhFGF-10 to Penetrate the Skin}

Recombinant proteins were applied to the skin and then detected by immunohistochemistry. First, we observed the absorption of the recombinant protein preparations into the surface of the skin. The absorption of prokaryotically-expressed rhFGF-10 was slow, and less of the preparation was absorbed; the surface of the skin in this group remained covered with a layer of protein which made the skin appear white. However, the absorption of oil body-bound oleosin-rhFGF-10 was better. After approximately $30 \mathrm{~min}$, more than $90 \%$ of the preparation had been absorbed, and after $60 \mathrm{~min}$, the preparation had been completely absorbed by the skin (Figure 3a). Next, immunohistochemistry was used to stain absorbed protein within the skin (Figure 3b). At times from 0 to $30 \mathrm{~min}$, the positive protein was mainly concentrated in the epithelial cells. The staining intensity in the oleosin-rhFGF-10 group was greater than that in the rhFGF-10 group. More absorbed protein could be observed in the subepidermal tissue of the oleosin-rhFGF-10 group than that of the rhFGF-10 group, and its staining intensity was stronger. At times from 30 to $60 \mathrm{~min}$, most of the protein had been absorbed, and was mainly concentrated in hair follicles, we observed the staining intensity had no significant change (Figure $3 b$ ). We analyzed the content of positive protein in skin by western blotting, and found that more positive protein was detected in the oleosin-rhFGF-10 group compared with the rhFGF-10 group (Figure 3c). But after $30 \mathrm{~min}$, the positive protein was still being absorbed in the rhFGF-10 group, and the content of positive proteins reached maximum absorption at $45 \mathrm{~min}$. In the oleosin-rhFGF-10 group, the content of positive proteins reached maximum absorption at $30 \mathrm{~min}$, and the content of positive proteins remained stable. The stability of the proteins was possibly related. These data show that the oleosin-rhFGF-10 rapidly penetrated the skin and was absorbed faster than rhFGF-10. 


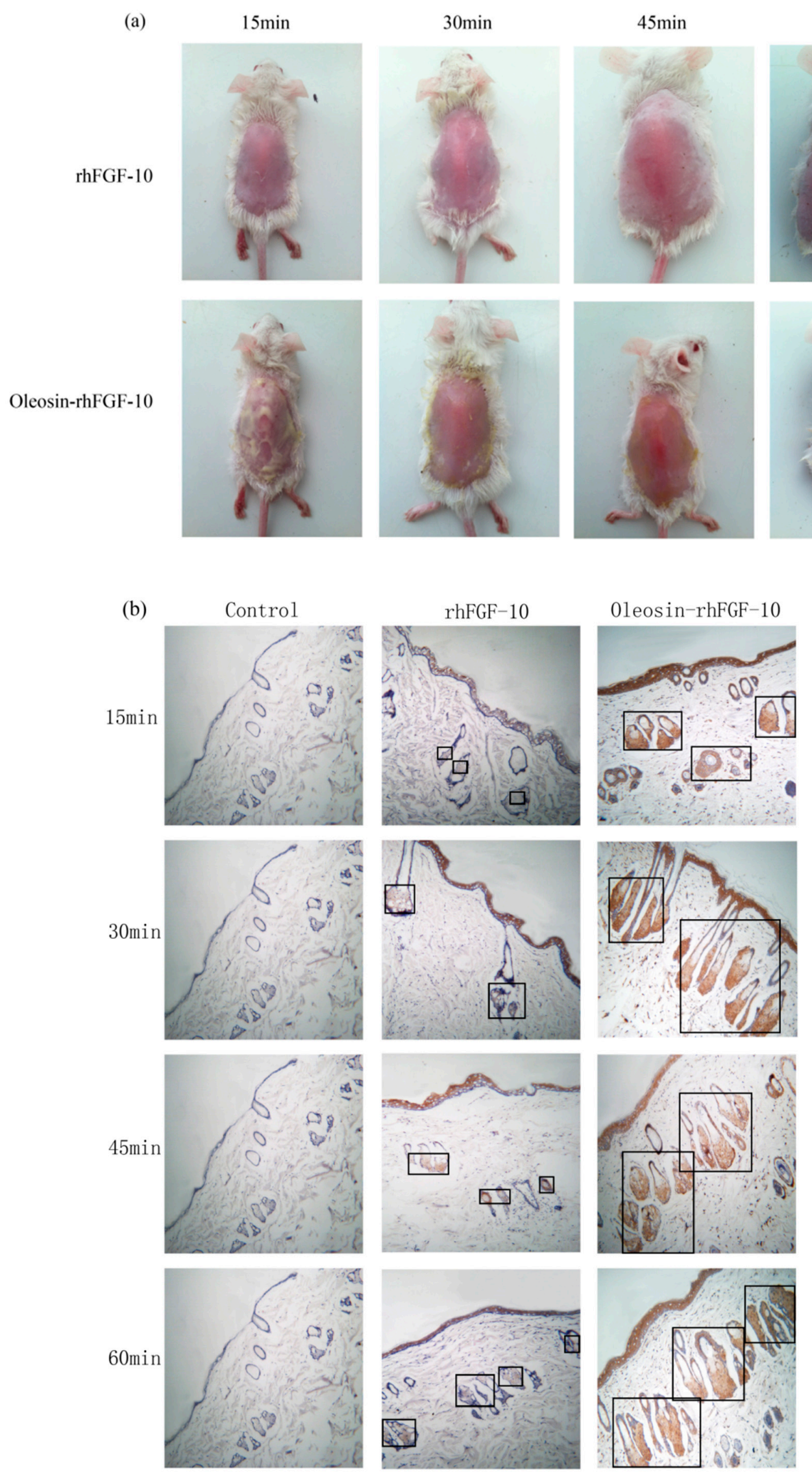

Figure 3. Cont. 
(c)
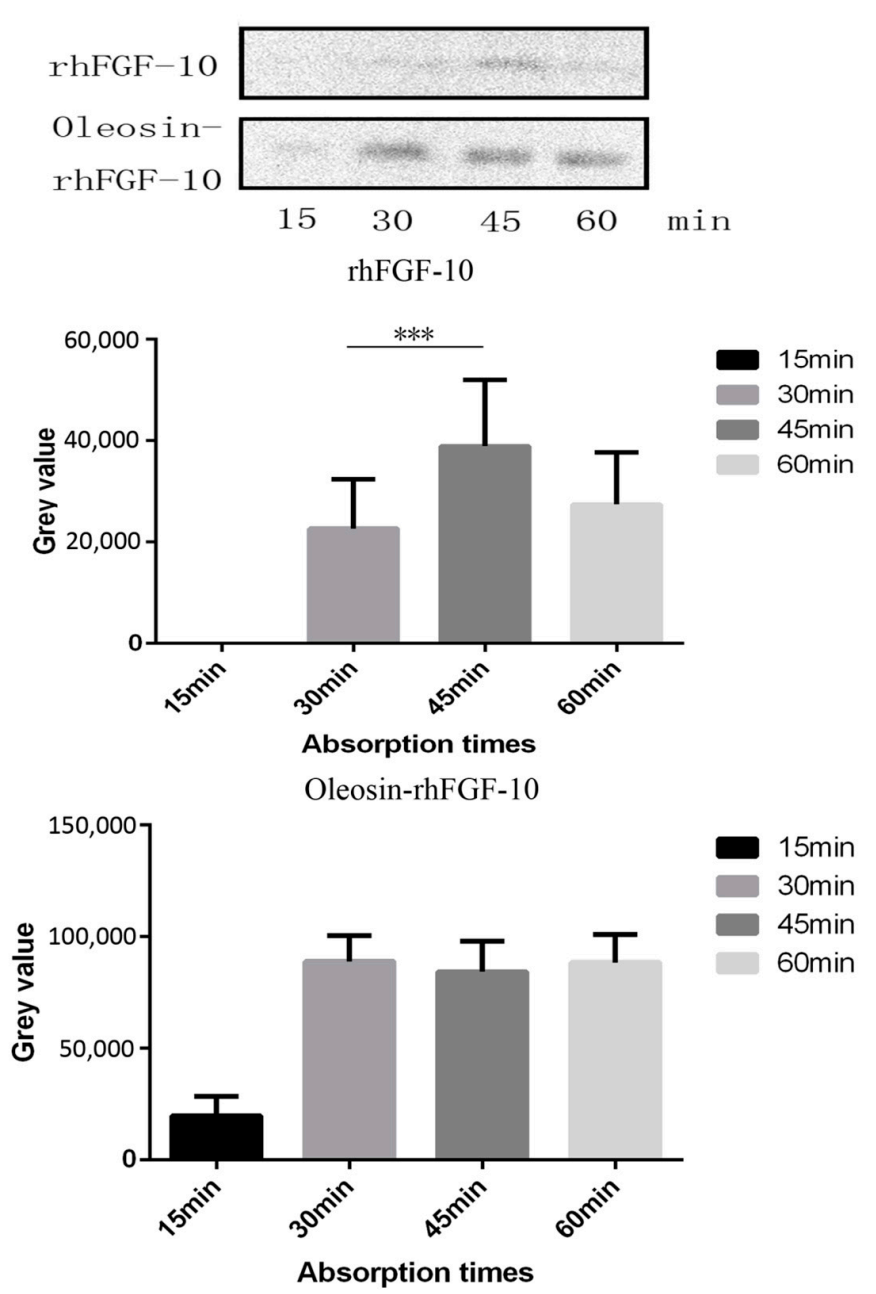

Figure 3. The ability of oleosin-rhFGF-10 to penetrate the skin. (a) The effectiveness of drug absorption into skin at different times, as evaluated by photography; (b) skin sections were stained for oleosin-rhFGF-10 by immunohistochemistry. The positive protein is stained brown and is marked by the black boxes; (c) the western blotting quantification method for objective evaluation in skin. The images are shown at $400 \times$ magnification. ${ }^{* * *} p<0.001$.

\subsection{Oleosin-rhFGF-10 Enhances Wound Closure}

To evaluate the bioactivity of oleosin-rhFGF-10 in promoting cutaneous wound healing, we created full-thickness cutaneous wounds in C57BL/ 6 mice. Figure 4a shows photographs of wounds in the four treatment groups on days $0,5,10$ and 15. It can be seen that the phosphate-buffered saline (PBS) and WT oil body-treated wounds showed similar closure rates throughout the treatment process $(p>0.05)$. The wounds that were treated with rhFGF-10 protein and with an oil body extract containing oleosin-rhFGF-10 showed accelerated closure compared with the PBS and WT groups on days 10 $(p<0.001, p<0.001)$ and $15(p<0.05, p<0.05)$. On day 10, wounds treated with the oleosin-rhFGF-10 had closed more than those treated with rhFGF-10 $(p<0.05)$. After 15 days of oleosin-rhFGF-10 treatment, the surfaces of wounds were entirely healed and appeared almost scarless. The closure rates were compared among the four groups by quantitative analysis (Figure $4 \mathrm{~b}$ ). The wound closure rate in oleosin-rhFGF-10-treated mice was higher than the other three groups at all treatment times (days 5, 10 and 15). By day 15, the final wound closure rates were $94.5 \pm 1.1 \%$ for the oleosin-rhFGF-10 group, $91.9 \pm 1.4 \%$ for the rhFGF-10 group, $87.4 \pm 4.4 \%$ for the WT group and $84.5 \pm 3.5 \%$ for the PBS group. 

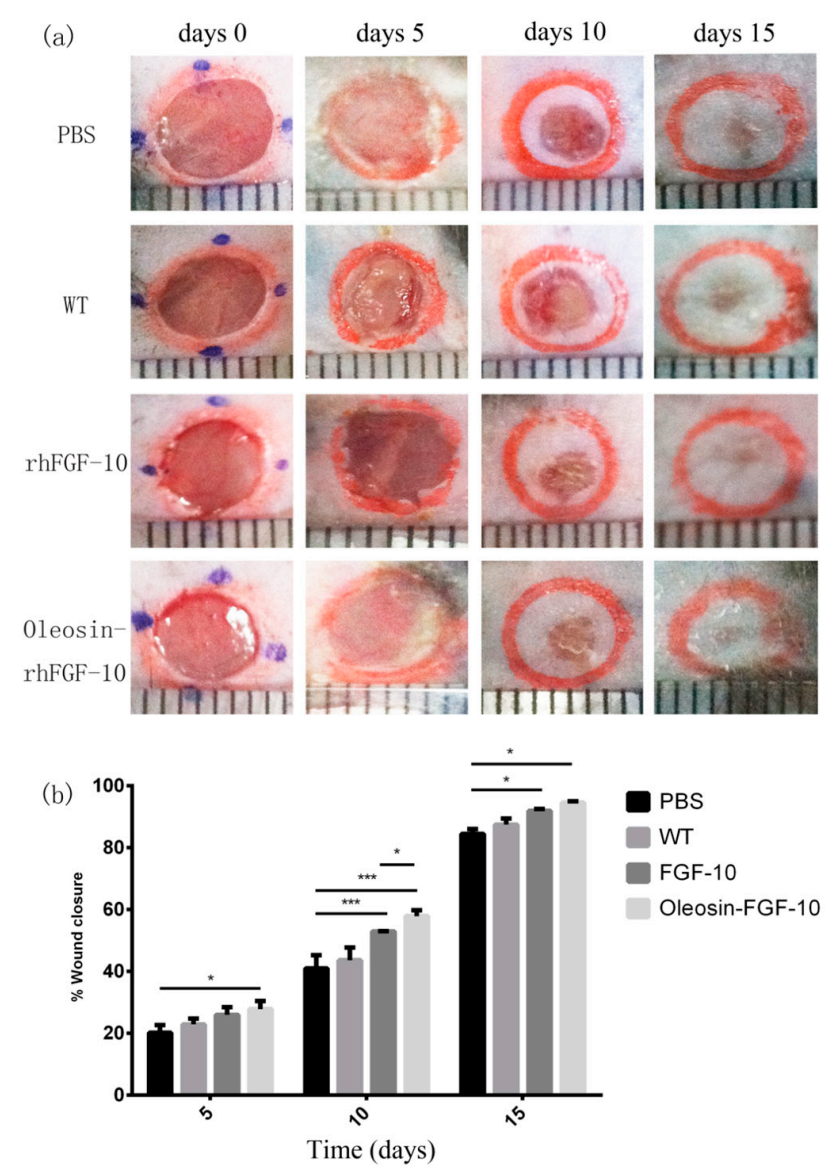

Figure 4. Oleosin-rhFGF-10 enhances wound closure. (a) Photographs of wounds receiving four treatments, on days $0,5,10$ and 15 . The scales shown at the bottom of each image are $\mathrm{mm}$; (b) wound closure rates were quantified and statistically analyzed. Significant differences between the treatment groups $(n=6)$ were determined. ${ }^{* *} p<0.001, * p<0.05$.

\subsection{Oleosin-rhFGF-10 Induces More Subcutaneous Tissue Formation}

For clinical observation and histological analysis of skin regeneration, mice were randomly selected from each group and euthanized on days 10 and 15 . Figure 5 a shows the hematoxylin and eosin (H\&E) stained histology for the four treatment groups. On day 10, in rhFGF-10 and oleosin-rhFGF1-10 groups, the wound areas had begun to close and we could observe the regeneration of the epidermis. On the other hand, regeneration was not complete in the rhFGF-10 groups, which showed fewer hair follicles and other skin appendages. On day 15, the wounds had failed to heal perfectly in the PBS and WT groups, but in the oleosin-rhFGF-10 and rhFGF-10-treated groups, complete regeneration of the skin structure was seen. However, the hair follicles and blood vessels had regenerated and were well-integrated with surrounding regions. The connectives tissue was dyed red in the oleosin-rhFGF-10 group deeper than in the rhFGF-10 group.

Sections of wounds were also stained using Masson's trichome to evaluate collagen deposition in the regenerating skin. On day 10, wounds treated with oleosin-rhFGF-10 showed much greater collagen deposition and appendage density than the other three groups (Figure 5b). At day 15, the extent of collagen deposition and thickness of the collagen layer in the subepidermal wound tissue made the skin structure more complete, especially in the vicinity of the epidermis. In contrast, less collagen formation was observed in the PBS and WT groups, and the dense degree of collagen was lost. Similar results were seen with the H\&E staining, shown in Figure 5. Thus, the oleosin-rhFGF-10 accelerated wound healing by increasing reepithelialization, subepidermaltissue formation and collagen deposition. 

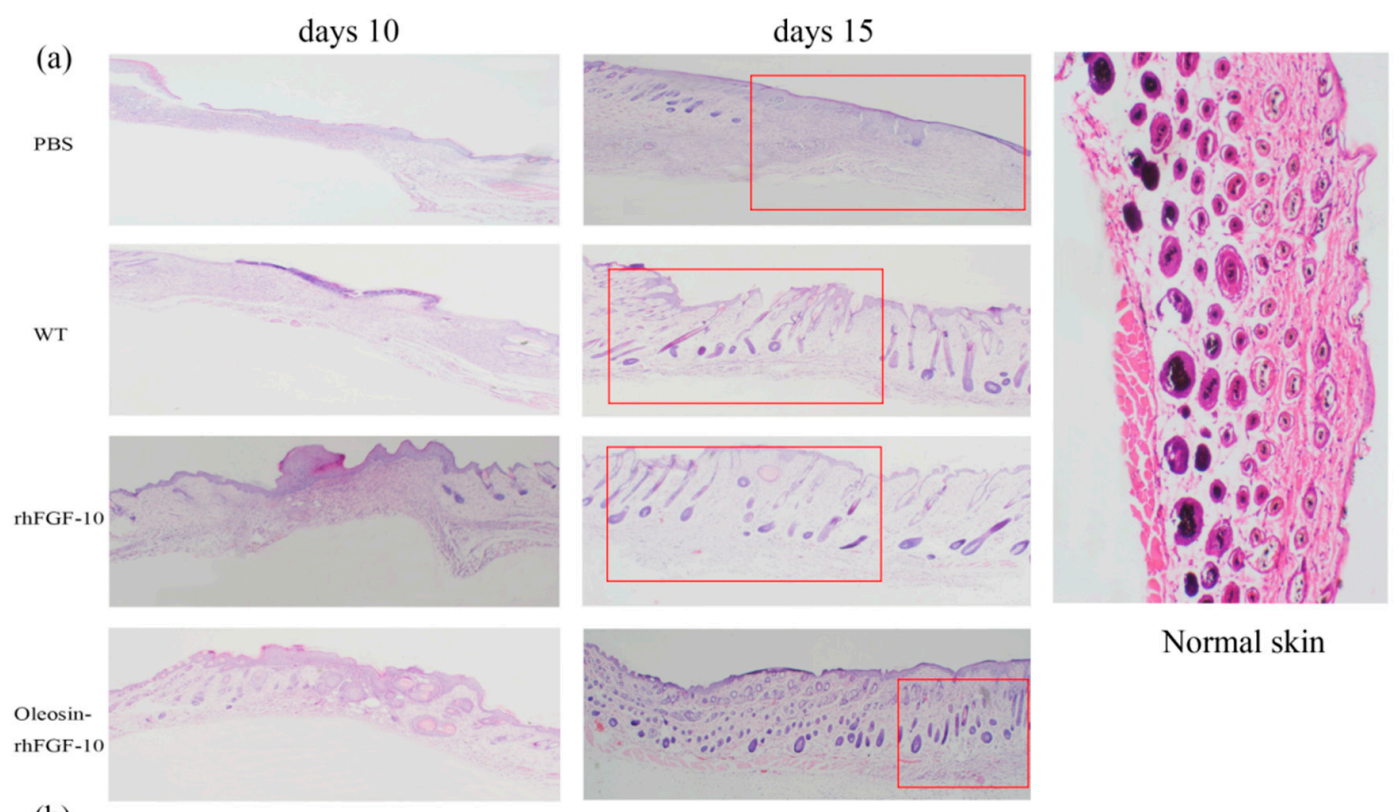

Normal skin
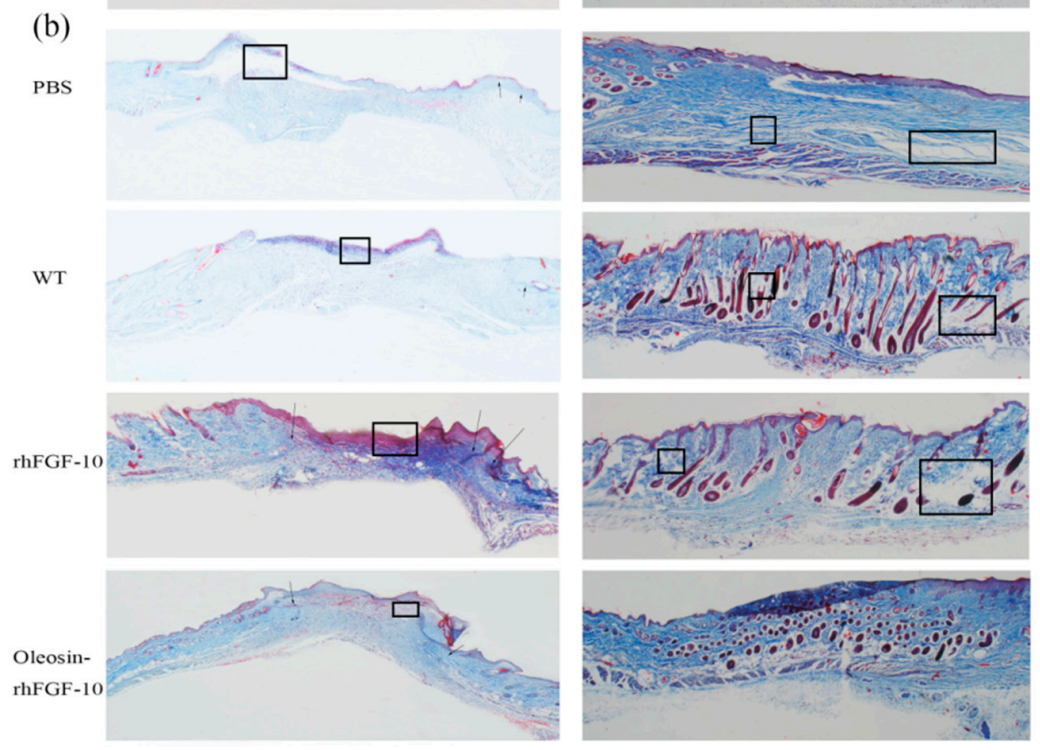

Figure 5. (a) Histological analysis of wound sites. Sections of wound skin at two time points following four treatments were stained with hematoxylin and eosin. The images are shown at $40 \times$ magnification; (b) collagen deposition in wound sites. Sections of wound skin at two time points following four treatments were stained with Masson's trichrome. The unrepaired parts were marked by the black boxes and repair parts are marked by the arrows. The wound areas were marked by red boxes. The images are shown at $40 \times$ magnification.

\subsection{Oleosin-rhFGF-10 Promotescytokeratin-10 and IL-2 Expression}

Cytokeratin-10 was further used as a stained mark to evaluate re-epithelialization. Consistent with the HE and Masson results, the epidermis regeneration of skin wounds were not, or were least, observed in both PBS and the WT at 10 and 15 days; and the oleosin-rhFGF-10 treated wounds showed much thicker epithelia layers than rhFGF-10 treated wounds from days 10 to 15 . Meanwhile, the number of skin appendages in the oleosin-rhFGF-10 group was more than the other three groups (Figure 6a). From days 1 to 3, the content of IL-2 (Interleukin-2) was in a downward trend in the PBS and WT rhFGF-10 groups; but in the oleosin-rhFGF-10 group the content of IL-2 was on the rise. From days 5 to 14, the content of IL-2 was on the rise; at day 14, IL-2 in the rhFGF-10 (72.0\%) 
and oleosin-rhFGF-10 (79.4\%) groups was higher than in the PBS (56.6\%) and WT (57.6\%) groups, which were closer to the content of IL-2 (81.2\%) in normal mice (Figure 7).

Taken together, the oleosin-rhFGF-10 exhibited an improved healing effect on re-epithelialization, granulation tissue formation, and collagen deposition. IL-2 levels in the body in general have the potential to impact the process of wound healing. So when the skin is damaged at days 1 to 3 , the oleosin-rhFGF-10 can sustain high levels of the IL-2 in order to promote wound healing. At day 14, the levels of IL-2 in the oleosin-rhFGF-10 group was higher than other three groups, and it promoted wound healing better than other groups.

(a)

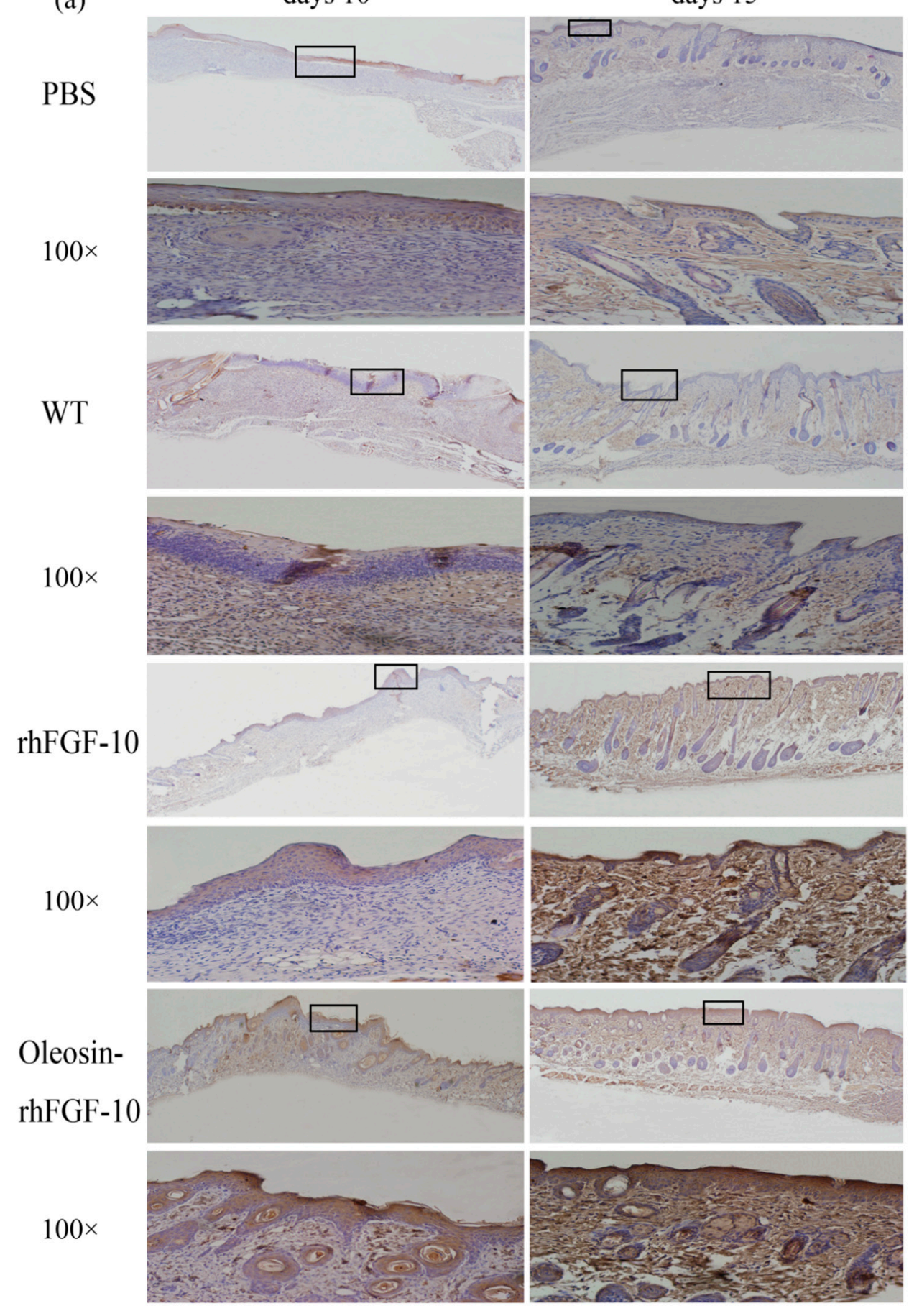

Figure 6. Cont. 
(b)

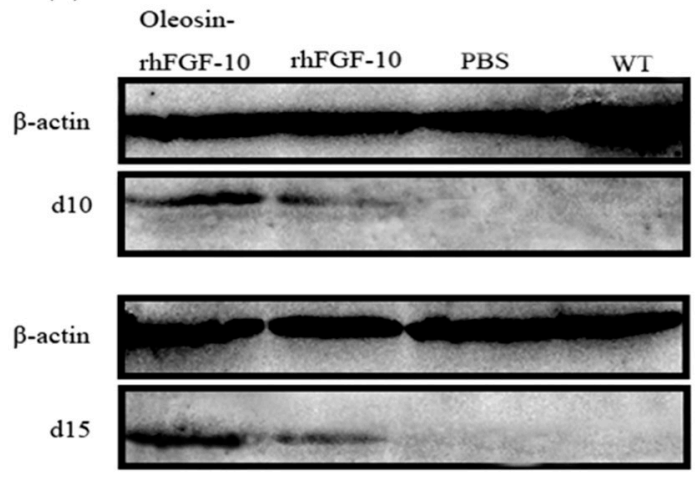

(c)

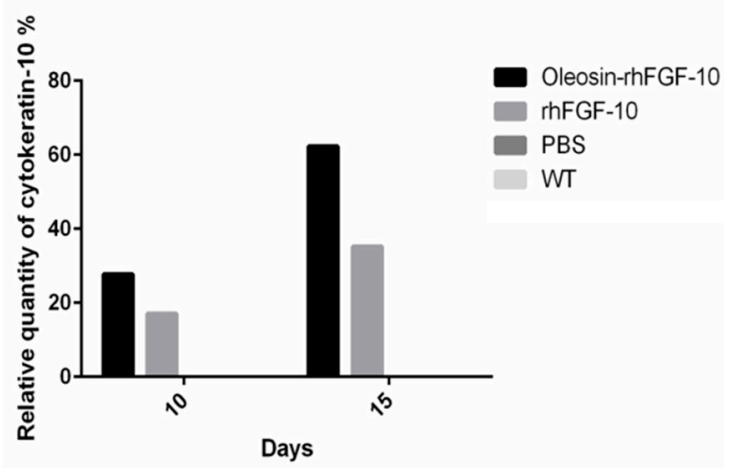

Figure 6. (a) Immunohistochemical assay with thecytokeratin-10 in wounds of the four groups. The cytokeratin-10 was detected in regenerated epidermis. The images are shown at $40 \times$ and $100 \times$ magnification; (b,c) western blot quantification method for objective evaluation for expressing cytokeratin-10 in regenerated skin.

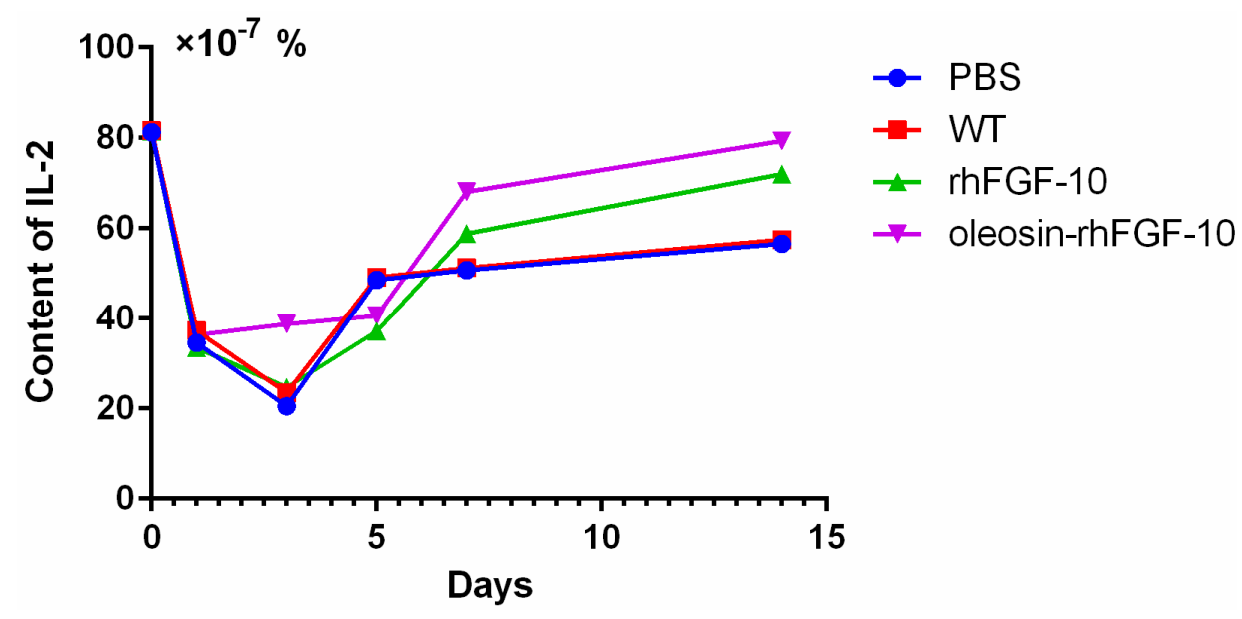

Figure 7. IL-2 was measured by enzyme-linked immunosorbent assay (ELISA) in the process of wound healing. Mice were randomly selected from each group and euthanized on days 1, 3, 5, 7 and 14. The entire experiment was repeated three times and results were expressed through a mean.

\subsection{The Effect of Oleosin-rhFGF-10 on Hair Growth}

To test the hair growth activity of oleosin-rhFGF-10, we applied PBS, WT oleosin, rhFGF-10 and oleosin-rhFGF-10 to a C57BL/ 6 mouse alopecia model for 15 days. Every 5 days, we observed shades of color on the dorsum to evaluate the extent of hair growth (Figure 8). At day 10, the oleosin-rhFGF-10 group showed the blackest coloration of the groups, and a few newly emerging hairs could be observed. In contrast, less hair growth was seen in the PBS and WT groups, which was associated with less black coloration. At day 15, the rhFGF-10 and oleosin-rhFGF-10 groups showed dense hair growth, and their hair coverage rate was over $90 \%$, compared with coverage rates of less than $50 \%$ in the PBS and WT groups.

We observed hair regeneration in H\&E-stained skin sections. As shown in Figure 9a, the number of hairs regenerating in the rhFGF-10 and oleosin-rhFGF-10 groups was higher than in the other groups; and the length of hair follicles was greater in the oleosin-rhFGF-10 group compared with the other three groups, which was consistent with the results in Figure 8. Quantitatively, more hair regeneration was seen following treatment with oleosin-rhFGF-10 compared with rhFGF-10, WT oil body protein and PBS $(p<0.05, p<0.001, p<0.001)$ (Figure 10a). To evaluate the role of cytokeratin-14 induction in the mechanism of hair growth, cytokeratin-14 expression was detected by immunohistochemistry. 
The protein of interest was expressed in all four treatment groups, but the levels of cytokeratin-14 were higher in the oleosin-rhFGF-10 group compared with the other three groups, with much of the positive protein localized in the hair follicles (Figures $9 \mathrm{~b}$ and $10 \mathrm{~b}$ ).

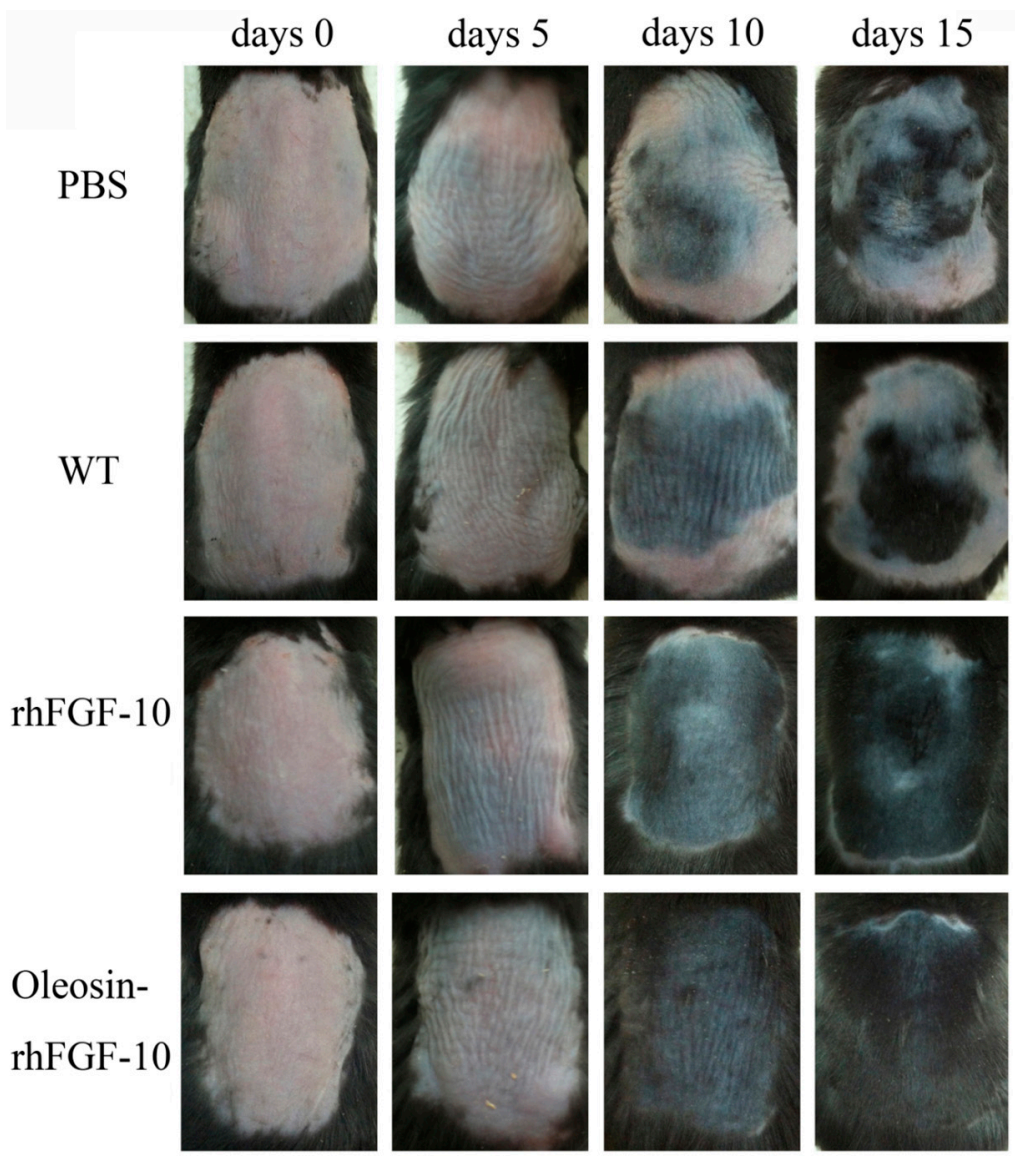

Figure 8. The effect of oleosin-rhFGF-10 on hair growth. Sequential photographs showing hair growth following four treatments, on days $0,5,10$ and 15 . The color of the skin changes from pink to black with the regeneration of hair follicles.

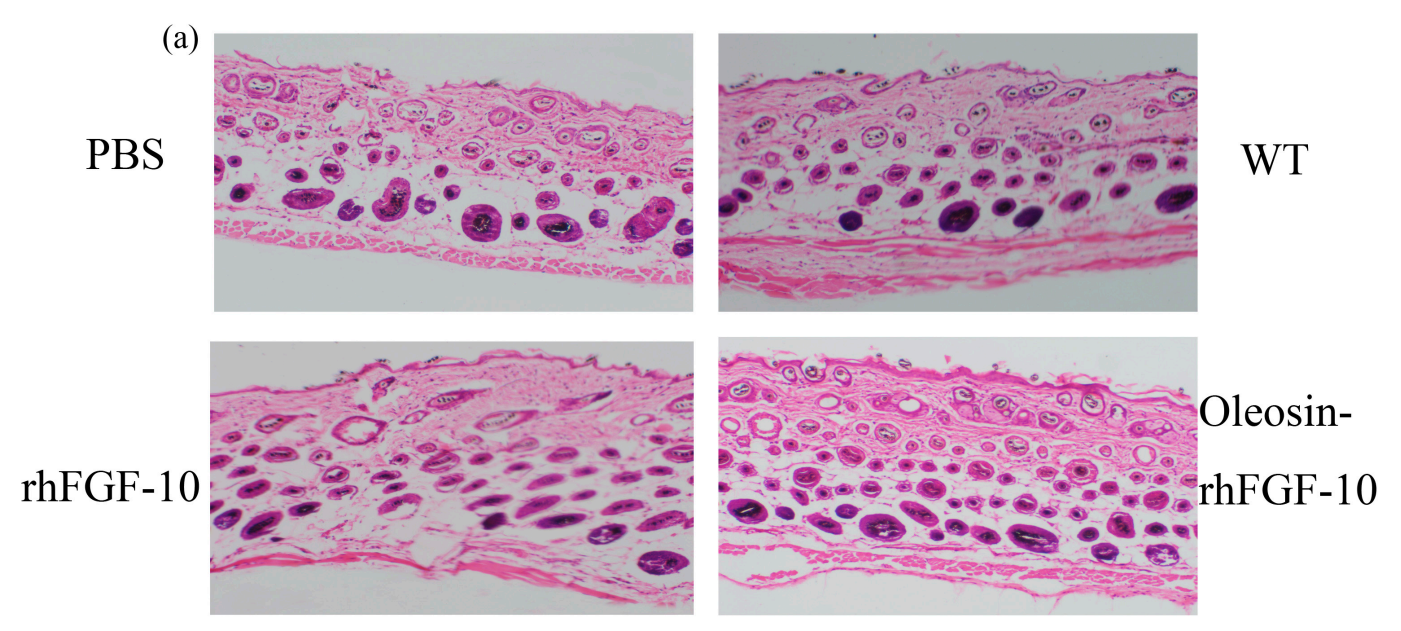

Figure 9. Cont. 

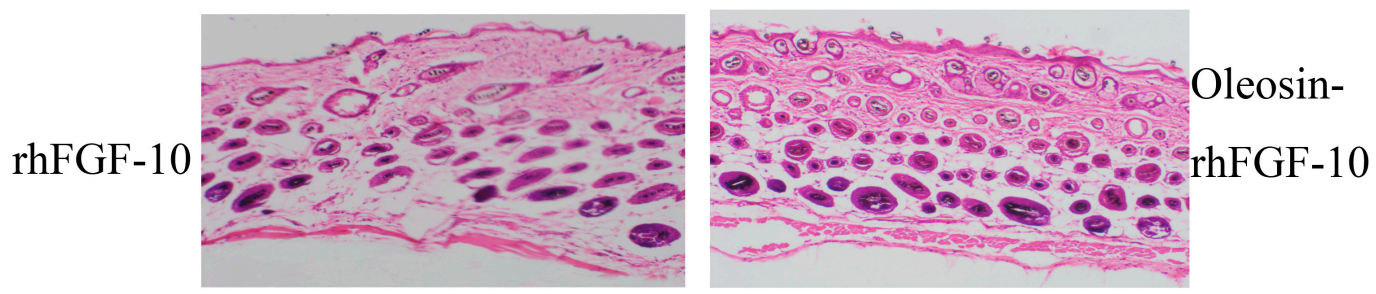

(b)
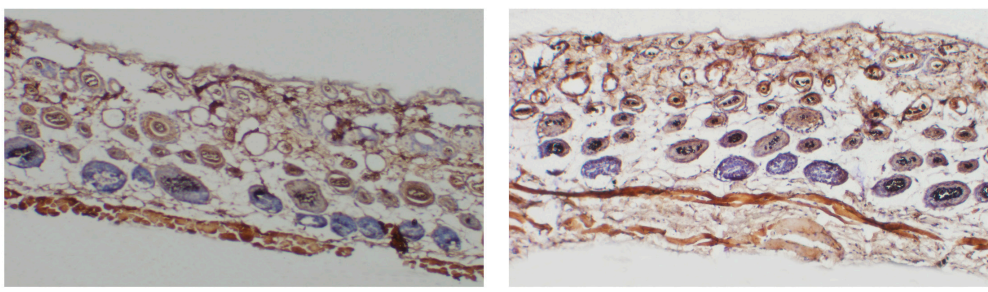

WT

PBS
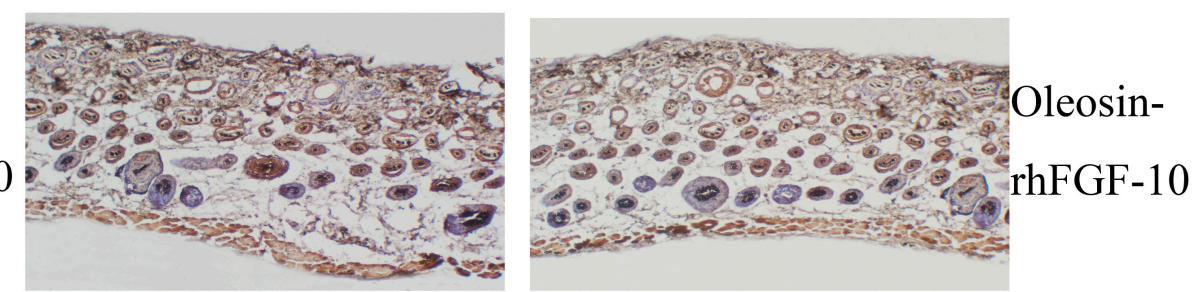

(c)

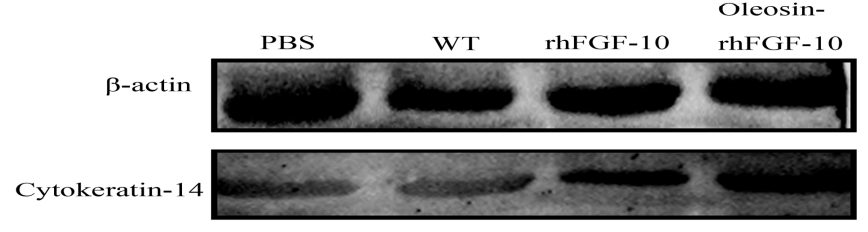

Figure 9. The effect of oleosin-rhFGF-10 on hair-follicle regeneration. (a) Images of hematoxylin- and eosin-stained skin sections following four treatments, showing hair regeneration on day 10. Images are shown at $100 \times$ magnification; (b) immunohistochemistry of the expression of cytokeratin-14; (c) western blot quantification method for objective evaluation for expressing cytokeratin-14 in skin.

(a)

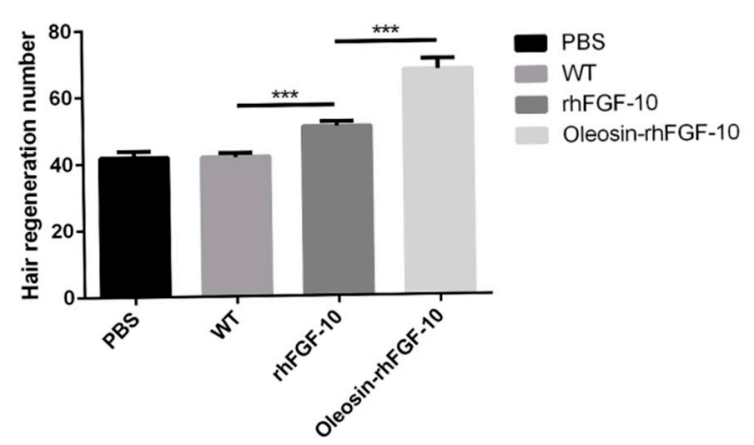

(b)

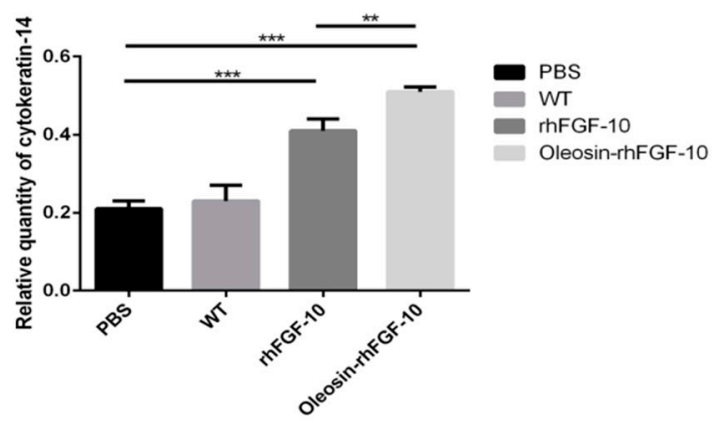

Figure 10. The number of regenerating hair follicles and expressing cytokeratin-14 were quantified. (a) Presenting the number of hair follicles; (b) the relative content ofcytokeratin-14. ${ }^{* *} p<0.001,{ }^{* *} p<0.05$.

\subsection{Stability of Oleosin-rhFGF-10}

To detect the potential resistance of oleosin-rhFGF-10 to proteolysis, the rhFGF-10 and oleosin-rhFGF-10 protein were incubated with trypsin for various time periods and then analyzed by sodium dodecyl sulfate polyacrylamide gel electrophoresis (SDS-PAGE) and western blotting. Figure 11a shows that, after incubation for $1 \mathrm{~min}$, rhFGF-10 had been degraded, and appreciable 
change was seen in the molecular size and intensity of the band. At $40 \mathrm{~min}$, rhFGF-10 had been fully digested. However, for oleosin-rhFGF-10, no significant degradation was observed from 1 to $60 \mathrm{~min}$, and there was no tendency for the band to change position (Figure $11 b, c)$. However, proteins with a molecular weight of less than or equal to $23 \mathrm{kDa}$ were digested. These results demonstrated that oleosin-rhFGF-10 is a stable protein and resistant to proteolysis.

(a)

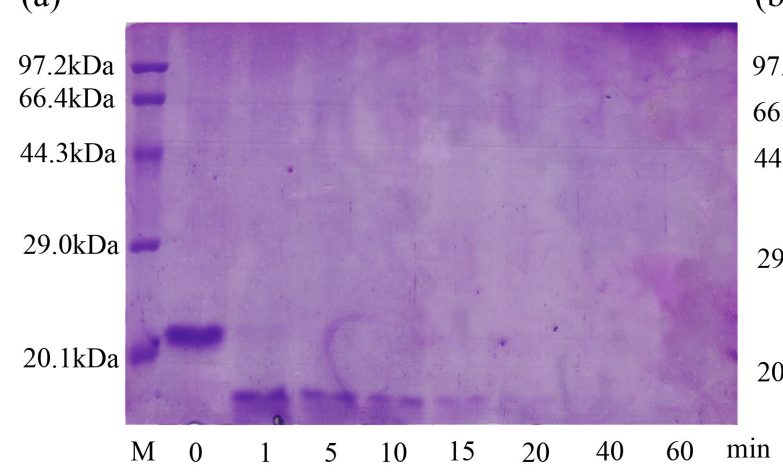

(b)

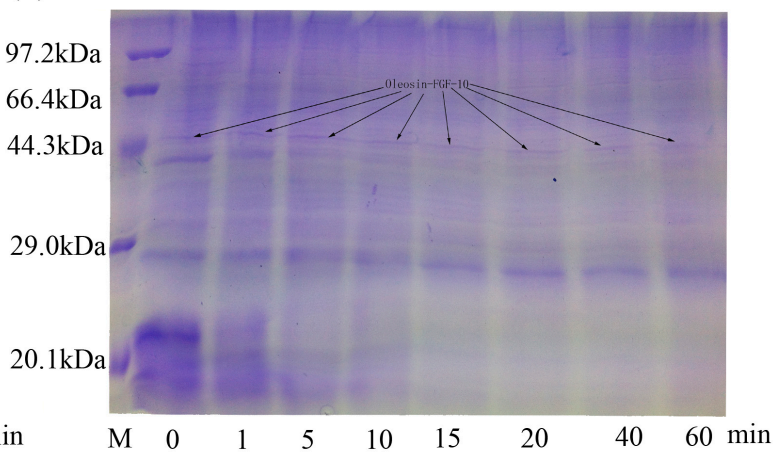

(c)

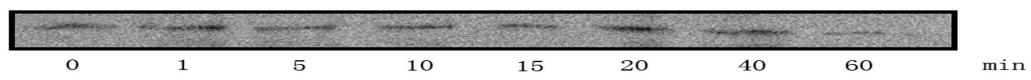

Figure 11. Sodium dodecyl sulfate polyacrylamide gel electrophoresis (SDS-PAGE) and western blot to analyze the proteolysis. (a) The method of SDS-PAGE to analyze the rhFGF-10; $(\mathbf{b}, \mathbf{c})$ the oleosinrhFGF-10 was detected by SDS-PAGE and western blot to confirm the stability of interest protein.

\section{Discussion}

FGF-10 has been shown to effectively promote epidermal regeneration, corneal wound healing, lung wound healing and hair growth $[2,3,5,16,17]$. The shortcomings of rhFGF-10 include its instability, poor skin absorption and short half-life. To overcome these disadvantages, we transferred an rhFGF-10 gene into safflowers to mediate expression of a fusion protein in their seeds. The pharmacological activity and advantages of this fusion protein were experimentally validated. First of all, the oleosinrhFGF-10 was used in a transdermal absorption test. The immunohistochemical results showed that the fusion protein better penetrated into the skin compared with unmodified rhFGF-10. The oleosin-rhFGF-10 preparation likely preserved the oil body structure, which mainly consists of three parts: the outer layer of phospholipids, abundant triacylglycerol, and oleosin protein, which is localized perpendicular to the surface of oil bodies and is responsible for the stability of the oil body [18]. Furthermore, the permeability barrier of skin, the stratum corneum, mostly consists of saturated lipids such as ceramide, cholesterol and free fatty acids. Oil bodies have a similar chemical composition, particularly with respect to fatty acids, which can improve their skin penetration ability [19]. The oil body integrates into the stratum corneum, leading to changes in lipid composition and structure, along with the appearance of cracks and holes on the skin surface that increase the permeability of skin and allow drugs to be more readily absorbed [20]. On the other hand, hair follicles and sebaceous glands are another important route of transdermal drug absorption [21]. In our study, the oil body protein appeared to be absorbed via the hair follicle-sebaceous gland route. The oil body-derived fusion domain of oleosin-rhFGF-10 likely increased fat-solubility and thereby improved its absorption via this route. As shown in Figure 3b, a large amount of oleosin-FGF-10 protein localized in hair follicles, and the intensity of staining was higher than for the other treatment groups. The large amount of positive protein concentrated in hair follicles is probably an important reason why oleosin-rhFGF-10 promoted hair growth better than the other treatments. Meanwhile, the oleosin-rhFGF-10 fusion protein showed increased resistance to proteolysis due to enhanced protein stability. The larger size of the fusion protein would raise its molecular volume, leading to reduced proteolytic enzyme-binding 
capacity, thereby protecting the protein from trypsin attack. Consistent with this, the results in Figure $11 \mathrm{~b}$ show that proteins of less than or equal to $23 \mathrm{kDa}$ are easier for trypsin to digest. Moreover, it is possible that oleosin-rhFGF-10 bound on the surface of the oil body leads to aggregation in an insoluble form and thus cannot be degraded by trypsin; but when it is used as a topical application on skin, the structure of the oil body was destroyed and the oleosin-rhFGF-10 was released, so the oleosin-rhFGF-10 restored solubility so that it can penetrate skin to perform bioactivities.

One study has reported that the blood IL-2 levels in burn patients were increased on both day 1 and day 5 , and it can promote wound healing [22]. From days 1 to 3 and days 7 to 15, the oleosin-rhFGF-10 can make the IL-2 sustain high levels, which can promote wound healing better than other three groups. It is also possible that the oleosin-rhFGF-10 had better stability, so it can work better, lasts longer, and a strong immune response could to reduce the wound infection. At day 5, in the rhFGF-10 and oleosin-rhFGF-10 groups, the expression of IL-2 was lower than in the PBS and WT groups. As the wound begins to close and tissue started to regenerate, the strong immune response could be harmful and damage wound healing. At day 7 and onwards, when the wound had healed more, the IL-2 could promote wound healing rather than damaging it.

FGF-10 has been found in dermal papilla fibroblasts and its receptor, fibroblast growth factor receptor 2 (FGFR2), in the neighboring outer root sheath of keratinocytes. Application of rhFGF-10 at $10 \mathrm{ng} / \mathrm{mL}$ significantly stimulated human hair-follicle cell proliferation in organ culture (26-35\%) [4]. In this study, we created full-thickness cutaneous wounds in mice, which led to loss of hair follicles in the wound area. When we applied the oil body protein containing the oleosin-rhFGF-10 to treat the wounds, we found better curative effect in the oleosin-rhFGF-10 group than in the rhFGF-10 group, especially in promoting hair-follicle regeneration; meanwhile, the hair follicles regenerated made the wound healing more complete and the skin structure closer to the normal skin, reflecting another advantage of oleosin-rhFGF-10 in treating wound healing. Using the oil body as a drug delivery system could promote more oleosin-rhFGF-10 being absorbed in healed skin, hence more regenerated hair follicles in the oleosin-rhFGF-10 group than in the other three groups, and this may be relative to the stability of oleosin-rhFGF-10. For example, when applied in the treatment of head skin wounds, it might not only speed up wound healing, but also it could promote hair growth more quickly.

More generally, oil bodies as a delivery system can promote transdermal drug absorption, ferrying large molecules such as proteins into the skin and accelerating their uptake. They provide a new approach to solving the problems associated with inducing macromolecular protein drugs to cross the skin barrier. Furthermore, transgenic safflowers provide a new way to produce valuable medicinal proteins, in this case oleosin-rhFGF-10. The oleosin-rhFGF-10 effectively accelerated wound healing and hair growth in mice, suggesting it could be a possible new drug for the treatment of skin wounds and hair loss in humans. Finasteride and minoxidil are internationally approved for the treatment of hair loss, but their curative effects are unstable and they have side effects, which limits their more extensive use. Our oil body-oleosin-rhFGF-10 preparation not only efficiently promoted hair growth, but is also a natural product. There may be less toxicity and side effects of oil body proteins compared with synthetic drugs. Natural and green products developed as new drugs have good potential for application.

\section{Materials and Methods}

\subsection{Polymerase Chain Reaction (PCR) and Southern Blot Detection of the Oleosin-rhFGF-10 Gene in Safflower}

The T3 generation transgenic safflower used in this study was obtained from Jilin Agricultural University, China. The cetyl trimethylammonium bromide method was used to isolate genomic DNA from transgenic plants. PCR and Southern blotting were carried out using genomic DNA from T3 plants, with a pOTBar-oleosin-rhFGF10 plasmid (Jilin Agricultural University, Jilin, China) used as the positive control, WT safflower leaf DNA as the negative control, and double distilled water as the blank control. The PCR reaction program was: denaturation at $95^{\circ} \mathrm{C}$ for $5 \mathrm{~min} ; 30$ cycles of $95^{\circ} \mathrm{C}$ for $30 \mathrm{~s}$, 
$55{ }^{\circ} \mathrm{C}$ for $30 \mathrm{~s}, 72{ }^{\circ} \mathrm{C}$ for $1 \mathrm{~min}$; and a final extension at $72{ }^{\circ} \mathrm{C}$ for $10 \mathrm{~min}$. The rhFGF-10-specific primers used were: forward, $5^{\prime}$-ATAGGTACGCAACGGGAGA-3'; reverse, $5^{\prime}$-TGCCTTCACAGCGACAAC- $3^{\prime}$. The PCR products were characterized by $1 \%$ agarose gel electrophoresis. The identification of transgenic safflower genomes was verified by Southern blotting. A digoxigenin-UTP probe was synthesized using the pOTBar-oleosin-rhFGF10 plasmid as a template, with a DIG High Prime DNA Labeling and Detection Starter Kit I (DIG High Prime DNA Labeling and Detection Starter Kit I (for color detection with NBT/BCIP), 11585614910, Basel, Switzerland). The probe DNA was separated on a $\%$ agarose gel electrophoresis. It was then purified with a gel extraction kit (Biotake, Changchun, China). The genomic DNA was digested with HindIII and subjected to $0.8 \%$ agarose gel electrophoresis at $38 \mathrm{~V}$ for $11 \mathrm{~h}$. The gel was then placed in denaturing solution to denature the DNA, and the DNA was transferred to a nylon membrane by capillary blotting. The membrane was prehybridized at $43^{\circ} \mathrm{C}$ for $2 \mathrm{~h}$ and hybridized for $10 \mathrm{~h}$. The membrane was then incubated in blocking buffer at room temperature for $30 \mathrm{~min}$. Next, the membrane was incubated with anti-Dig-AP (1:5000) at $25^{\circ} \mathrm{C}$ for $30 \mathrm{~min}$, washed, and equilibrated in detection buffer for $5 \mathrm{~min}$. Finally, the membrane was incubated in nitro blue tetrazolium chloride/5-bromo-4-chloro-3-indolyl phosphate stock solution for $30 \mathrm{~min}$ and photographed to record the hybridization signals.

\subsection{Identification of the Fusion Protein}

Seeds harvested from transgenic safflowers $(0.5 \mathrm{~g})$ were crushed and ground in $1000 \mu \mathrm{L}$ of $0.01 \mathrm{M}$ phosphate buffered saline (PBS, $\mathrm{pH}$ 7.4) using a mortar and pestle, and then centrifuged for $10 \mathrm{~min}$ at $12,000 \times \mathrm{g}$. The aqueous phase was discarded and the hydrophobic phase was washed three times with PBS and centrifugation, after which the hydrophobic supernatant containing oil body protein material was collected. The transgenic safflowers oil body protein was a mix protein which contained the oleosin-rhFGF-10 protein, other oleosin and oil body; and the rhFGF-10 protein was highly purified protein (expressed in E. coli, supplied by the Wenzhou Medical University, Wenzhou, China); the wild-type safflower oil body protein only contained oleosin and oil body (supplied by the Jilin Agricultural University). Extracted oil body protein was denatured and the oil body broken up by heating, separated on $12 \%$ polyacrylamide electrophoresis gels and western blotted onto PVDF membranes. The membrane was blocked in $5 \%$ skim milk for $2 \mathrm{~h}$, then incubated with poly-clonal rabbit anti-rhFGF-10 (ab71794, 1:1000, Abcam, Shanghai, China) at $4{ }^{\circ} \mathrm{C}$ overnight. The membrane was washed three times with PBS-tween 20 (PBST), 10 min per wash. Next, the membrane was incubated with horse radish peroxidase (HRP) conjugated goat anti-rabbit antibody (bs-0295G-HRP, 1:1000, Bioss, Beijing, China) at room temperature for $1 \mathrm{~h}$ and washed in PBST as above. Signals were detected by enhanced chemiluminescence. The concentration of oleosin-rhFGF-10 was determined using a human KGF-2 enzyme-linked immunosorbent assay (ELISA) kit (Baijin Biotechnology Co., Ltd., Changchun, China).

\subsection{Mouse Model}

C57BL/6 (20 $\pm 2 \mathrm{~g})$ and BALB/c mice (20 $\pm 2 \mathrm{~g})$ were purchased from Changchun Billion Biotechnology Limited Company (Changchun, China). The mice were housed in normal laboratory conditions (temperature, $23 \pm 2{ }^{\circ} \mathrm{C}$, humidity, 40-60\%, photoperiod, $12 \mathrm{~h}$ light and $12 \mathrm{~h}$ darkness) with free access to a standard diet and water. The animals were allowed to adjust to their new environment for one week. The investigation conforms with the Guide for the Care and Use of Laboratory Animals published by the US National Institutes of Health (NIH Publication No. 85-23, revised 1996). The experiment was authorized by Jilin Agricultural University ethical committee.

\subsection{The Ability of Oil Body to Promote the Oleosin-rhFGF-10 to Penetrate the Skin of Mice}

Healthy male BALB/c mice were randomly divided into three groups ( $n=6$ per group) and anesthetized with $4 \%$ chloral hydrate $(0.02 \mathrm{~mL} / \mathrm{g})$. Hair was removed from their dorsum. The PBS group was treated with $0.01 \mathrm{M}$ PBS (pH 7.4), the rhFGF-10 group with $0.2 \mu \mathrm{g} / \mu \mathrm{L}$ rhFGF-10 [23], 
and the oleosin-rhFGF-10 group with $143 \mu \mathrm{g} / \mu \mathrm{L}$ oil body extract containing oleosin-rhFGF-10 at $0.2 \mu \mathrm{g} / \mu \mathrm{L}$. After 15, 30, 45 or $60 \mathrm{~min}$, the mice were euthanized by cervical dislocation. The dorsal skin was photographed, and then processed for immunohistochemical staining to detect rhFGF-10 and oleosin-rhFGF-10 protein. The rest of the skin tissues were analyzedby western blotting. The total proteins were extracted with a Total Protein Extraction Kit (Solarbio, Beijing, China). Separated on 12\% polyacrylamide electrophoresis gels and western blotted onto PVDF membranes, $30 \mu \mathrm{g}$ protein was used to analyze each sample. The Quantity One software (Bio-Rad, Hercules, CA, USA) was used to analyze the gray degree values of the signals.

\subsection{Effect of Oleosin-FGF-10 on Mouse Skin Wound Healing}

Healthy male C57BL/ 6 mice were randomly divided into four groups ( $n=6$ per group). The mice were anesthetized by intraperitoneal injection of $4 \%$ chloral hydrate $(0.02 \mathrm{~mL} / \mathrm{g})$. Hair was shaved and then a depilatory cream was evenly applied on the dorsum, which was then cleansed with $75 \%$ ethanol for surface sterilization. Two full-thickness cutaneous wounds were made with a scalpel, one on either side of the spine. The PBS group was treated with0.01 M PBS (pH 7.4); the WT group with $357 \mathrm{mg} / \mathrm{L}$ oil body extract; the rhFGF-10 group with $0.5 \mathrm{mg} / \mathrm{L}$ rhFGF-10 [24]; and the oleosin-rhFGF-10 group with $357 \mathrm{mg} / \mathrm{L}$ oil body extract containing oleosin-rhFGF-10 at $0.5 \mathrm{mg} / \mathrm{L}$. ATegaderm ${ }^{\mathrm{TM}}$ transparent dressing (3M Health Care, Brookings, Washington, DC, USA) was then applied to the wounds to avoid infections and keep the surface of the wound from becoming wet. These treatments were repeated once every day. Mice were kept in separate cages. Photographs of the wound site at different time points were used to calculate the wound closure rate by using Image-Pro Plus 6.0 (Media Cybernetics, Inc., Rockville, MD, USA) software to trace the wound margin.

On the tenth day after wounding, three mice were randomly selected from every group and euthanized; the remaining mice were euthanized on day 15. The regeneration of wounds and surrounding tissues was examined histologically. Wound closure was quantified according to the following equation.

$$
\text { Wound closure }=\frac{\text { area of original wound }- \text { area of acture wound }}{\text { area of original wound }} \times 100 \%
$$

\subsection{IL-2 Enzyme-Linked Immunosorbent Assay (ELISA)}

ELISA of IL-2 was performed using the Mouse IL-2 ELISA Kit (bsk00030, Bioss, Beijing, China) and following the manufacturer's instructions.

\subsection{Effect of Oleosin-rhFGF-10 on Hair Growth}

Healthy male C57BL $/ 6$ mice were randomly divided into four groups ( $n=6$ per group). The mice were anesthetized by intraperitoneal injection of $4 \%$ chloral hydrate $(0.02 \mathrm{~mL} / \mathrm{g})$. Hair on the dorsum was shaved with electric clippers, and a hair removal cream was used to remove subcutaneous hairs to establish an alopecia model. The PBS group was given 0.01 M PBS (pH 7.4); the WT group was given $7.14 \mathrm{mg} / \mathrm{L}$ oil body extract; the rhFGF-10 group was given $0.01 \mathrm{mg} / \mathrm{l}$ rhFGF-10 [4]; and the oleosin-rhFGF-10 group was given $7.14 \mathrm{mg} / \mathrm{L}$ oil body extract containing oleosin-rhFGF-10 at $0.01 \mathrm{mg} / \mathrm{L}$. After a $30 \mathrm{~min}$ wait to allow for the drug to fully absorb, the mice were returned to their cages. The treatment was repeated once every day. The condition of hair growth on the dorsum of the mice was observed and photographed. The mice were euthanized on day 10 , and skin samples were taken for histological analysis of hair regeneration. From each treatment group, six representative histological sections were randomly selected for quantitative analysis of the number of regenerating of hair follicles. Differences between groups were compared by statistical analysis. Cytokeratin-14 expression in similar sections was evaluated by immunohistochemistry and western blot. 


\subsection{Effect of Oleosin on Enzymatic Hydrolysis of rhFGF-10}

rhFGF-10 and oleosin-rhFGF-10 were compared, each at eight time points. PBS (100 $\mu \mathrm{L}, 0.01 \mathrm{M}$, $\mathrm{pH} 7.4$ ) was added to $50 \mu \mathrm{g}$ rhFGF-10 or $50 \mu \mathrm{g}$ total oleosin including oleosin-rhFGF-10. The rhFGF-10 and oleosin-rhFGF-10 were incubated with trypsin $(2 \mathrm{mM})$ in a volume ratio of 100:1 protein: trypsin at $37^{\circ} \mathrm{C}$ for the times indicated. Next, $5 \times$ loading buffer was added and the protein and trypsin were denatured at $100{ }^{\circ} \mathrm{C}$ for $10 \mathrm{~min}$. After completing them, the samples were then subjected to sodium dodecyl sulfate polyacrylamide gel electrophoresis (SDS-PAGE) and western blot to evaluate the degradation of protein.

\subsection{Histological Analysis}

Skin samples were $1 \mathrm{~cm} \times 1 \mathrm{~cm} \times 0.15 \mathrm{~cm}$, and were fixed in $0.01 \mathrm{M}$ PBS (pH 7.4) containing $4 \%$ paraformaldehyde for $8 \mathrm{~h}$ and then routinely processed to wax. Sections were cut at $5 \mu \mathrm{m}$ and adhered to poly-L-lysine coated glass slides. The histology of subcutaneous tissues was analyzed with H\&E staining (Solarbio, Beijing, China), or with Masson's trichrome staining (Solarbio, Beijing, China) for the evaluation of collagen content in healing wounds.

\subsection{Immunohistochemical Staining}

Sections were dewaxed, hydrated and pretreated with $3 \% \mathrm{H}_{2} \mathrm{O}_{2}$ for 15 min to quench endogenous peroxidase activity, and then washed three times with PBS, 5 min per wash. Antigen retrieval was performed at high temperature and pressure in 0.01 Msodium citrate buffer for $10 \mathrm{~min}$. Nonspecific antibody binding was blocked with PBS containing 5\% bovine serum for $60 \mathrm{~min}$ at room temperature. Next, the sections were incubated with the primary antibody, either rabbit polyclonal anti-FGF-10 (sc-7179, 1:100, Santa Cruz Biotech, Santa Cruz, CA, USA); rabbit polyclonal anti-cytokeratin-10 (bs-11186R, 1:200, Bioss, Beijing, China); or rabbit polyclonal anti-cytokeratin-14 (bs-17922R, 1:250, Bioss, Beijing, China), at $4{ }^{\circ} \mathrm{C}$ overnight, and then with the secondary antibody, HRP-conjugated goat anti-rabbit (bs-0295G-HRP, 1:1000, Bioss, Beijing, China), for $2 \mathrm{~h}$ at room temperature. Antibody binding was detected with a DAB chromogen kit (Solarbio, Beijing, China) and the sections were counter stained with H\&E.

\subsection{Statistical Analysis}

Data are expressed as the mean \pm standard deviation. Data were analyzed using one-way analysis of variance followed by Tukey's test, using GraphPad Prism 5 software (GraphPad Software Inc., La Jolla, CA, USA).

Acknowledgments: We would like to thank the National High Technology Research and Development Program of China (863 Program) (No. 2011AA100606); the Innovation fund for medium-sized and small enterprises, Ministry of Science and Technology (13C26212201223); the National Natural Science Foundation of China (No. 31501366); and the Science and Technology Development Project of Jilin province (No. 20150623024TC-11, 20170520089JH) for providing funding to support our study.

Author Contributions: Chao Jiang and Xiaokun Li conceived and designed the experiments; Wenqing Li performed the experiments, analyzed the data and wrote the manuscript; Jing Yang guided the experiments and wrote the manuscript; Jingbo Cai, Hongyu Wang, Haishan Tian, Jian Huang, Weidong Qiang, Linbo Zhang, Haiyan Li contributed reagents/materials/analysis tools.

Conflicts of Interest: The authors declare no conflict of interest.

\section{Abbreviations}

PCR

SDS-PAGE

PBS

WT

rhFGF-10
Polymerase Chain Reaction

Sodium dodecyl sulfate polyacrylamide gel

Phosphate buffer salt

Wild Type

Recombinant human fibroblast growth factor 10 


$\begin{array}{ll}\text { Oleosin-rhFGF-10 } & \text { Oleosin-Recombinant human fibroblast growth factor } 10 \\ \text { ELISA } & \text { Enzyme-Linked Immunosorbent Assay } \\ \text { DIG } & \text { Digoxigenin } \\ \text { NBT/BCIP } & \text { Nitroblue Tetrazolium/5-Bromo-4-Chloro-3-Indolyl Phosphate } \\ \text { AP } & \text { Alkaline Phosphatase } \\ \text { HRP } & \text { Horse radish peroxidase } \\ \text { DAB } & \text { Diaminobenzidine } \\ \text { PVDF } & \text { Polyvinylidene Fluoride }\end{array}$

\section{References}

1. Emoto, H.; Tagashira, S.; Mattei, M.G.; Yamasaki, M.; Hashimoto, G.; Katsumata, T.; Negoro, T.; Nakatsuka, M.; Birnbaum, D.; Coulier, F. Structure and expression of human fibroblast growth factor-10. J. Biol. Chem. 1997, 272, 23191-231914. [CrossRef] [PubMed]

2. Werner, S. Fibroblast growth factors in epithelial repair and cytoprotection. Philos. Trans. R. Soc. Lond. B Biol. Sci. 2004, 359, 753-757.

3. Jimenez, P.A.; Rampy, M.A. Keratinocyte growth factor-2 accelerates wound healing in incisional wounds. J. Surg. Res. 1999, 81, 238-242. [CrossRef] [PubMed]

4. Jang, J.H. Stimulation of human hair growth by the recombinant human keratinocyte growth factor-2 (KGF-2). Biotechnol. Lett. 2005, 27, 749-752. [CrossRef] [PubMed]

5. $\quad$ Lin, W.H.; Xiang, L.J.; Shi, H.X.; Zhang, J.; Jiang, L.P.; Cai, P.T.; Lin, Z.L.; Lin, B.B.; Huang, Y.; Zhang, H.L. Fibroblast growth factors stimulate hair growth through $\beta$-catenin and Shh expression in C57BL/6 mice. BioMed. Res. Int. 2015. [CrossRef]

6. Kovacs, D.; Cota, C.; Cardinali, G.; Aspite, N.; Bolasco, G.; Amantea, A.; Torrisi, M.R.; Picardo, M. Expression of keratinocyte growth factor and its receptor in clear cell acanthoma. Exp. Dermatol. 2006, 15, 762-768. [CrossRef] [PubMed]

7. Wang, Y.; Yuan, S.; Wang, P.; Liu, X.; Zhan, D.; Zhang, Z. Expression, purification, and characterization of recombinant human keratinocyte growth factor-2 in Pichia pastoris. J. Biotechnol. 2007, 132, 44-48. [CrossRef] [PubMed]

8. Martino, M.M.; Briquez, P.S.; Ranga, A.; Lutolf, M.P.; Hubbell, J.A. Heparin-binding domain of fibrin(ogen) binds growth factors and promotes tissue repair when incorporated within a synthetic matrix. Proc. Natl. Acad. Sci. USA 2013, 110, 4563-4568. [CrossRef] [PubMed]

9. Huang, Z.; Ni, C.; Chu, Y.; Wang, S.; Yang, S.; Wu, X.; Wang, X.; Li, X.; Feng, W.; Lin, S. Chemical modification of recombinant human keratinocyte growth factor 2 with polyethylene glycol improves biostability and reduces animal immunogenicity. J. Biotechnol. 2009, 142, 242-249. [CrossRef] [PubMed]

10. Jian, H.; Jing, Y.; Guan, L.; Yi, S.; Du, L.; Tian, H.; Guo, Y.; Feng, Z.; Zhen, L.; Li, H. Expression of bioactive recombinant human fibroblast growth factor 10 in Carthamus tinctorius L. seeds. Protein Expr. Purif. 2015. [CrossRef]

11. Li, H.; Jing, Y.; Chen, Y.; Guan, L.; Du, L.N.; Guo, Y.X.; Wang, W.; Wang, L.; Li, H.; Chao, J. Expression of a functional recombinant oleosin-human hyaluronidase hPH-20 fusion in Arabidopsis thaliana. Protein Expr. Purif. 2014, 103, 23-27. [CrossRef] [PubMed]

12. Moloney, M.M.; van Rooijen, G. Expression of epidermal growth factor in plant seeds. U.S. Patent 7091401, 15 August 2006.

13. Nykiforuk, C.L.; Boothe, J.G.; Murray, E.W.; Keon, R.G.; Goren, H.J.; Markley, N.A.; Moloney, M.M. Transgenic expression and recovery of biologically active recombinant human insulin from Arabidopsis thaliana seeds. Plant Biotechnol. J. 2006, 4, 77-85. [CrossRef] [PubMed]

14. Parmenter, D.L.; Boothe, J.G.; van Rooijen, G.J.; Yeung, E.C.; Moloney, M.M. Production of biologically active hirudin in plant seeds using oleosin partitioning. Plant Mol. Biol. 1995, 29, 1167-1180. [CrossRef] [PubMed]

15. Goldberg, R.B.; Barker, S.J.; Perez-Grau, L. Regulation of gene expression during plant embryogenesis. Cell 1989, 56, 149-160. [CrossRef]

16. Wang, X.; Zhou, X.; Ma, J.; Tian, H.; Jiao, Y.; Zhang, R.; Huang, Z.; Xiao, J.; Zhao, B.; Qian, H. Effects of keratinocyte growth factor-2 on corneal epithelial wound healing in a rabbit model of carbon dioxide laser injury. Biol. Pharm. Bull. 2010, 33, 971-976. [CrossRef] [PubMed] 
17. Lin, T.; Zhou, J.; Rong, L.; Seeley, E.J.; Pan, J.; Zhu, X.; Liu, J.; Wang, Q.; Tang, X.; Qu, J. Fibroblast growth factor-10 (FGF-10) mobilizes lung-resident mesenchymal stem cells and protects against acute lung injury. Sci. Rep. 2016, 6, 21642.

18. Frandsen, G.I.; Mundy, J.; Tzen, J.T.C. Oil bodies and their associated proteins, oleosin and caleosin. Physiol. Plant 2001, 112, 301-307. [CrossRef] [PubMed]

19. Čižinauskas, V.; Elie, N.; Brunelle, A.; Briedis, V. In TOF-SIMS analysis of sea buckthorn oil fatty acids skin penetration. In Proceedings of the Bbbb Conference on Pharmaceutical Sciences Strategies To Improve the Quality and PERFORMANCE of Modern Drug Delivery Systems, Helsniki, Finland, 10-12 September 2015.

20. Ghyczy, M. Chemical Composition of Liposomes and Its Influence on the Humidity of Normal Skin; Springer: Berlin/Heidelberg, Germany, 1992; pp. 308-314.

21. Betz, G.; Imboden, R.; Imanidis, G. Interaction of liposome formulations with human skin in vitro. Int. J. Pharm. 2001, 229, 117. [CrossRef]

22. Kowalvern, A.; Walenga, J.M.; Hoppensteadt, D.; Sharppucci, M.; Gamelli, R. L Interleukin-2 and interleukin-6 in relation to burn wound size in the acute phase of thermal injury. J. Am. Coll. Surg. 1994, 178, 357-362.

23. Jia, X.; Tian, H.; Tang, L.; Zheng, L.; Zheng, L.; Yang, T.; Yu, B.; Wang, Z.; Lin, P.; Li, X. High-efficiency expression of TAT-bFGF fusion protein in escherichia coli and the effect on hypertrophic scar tissue. PLoS ONE 2015, 10, e0117448. [CrossRef] [PubMed]

24. Xia, C.; Wei, H.U.; Wei, W.G.; Yan, S.; Yan, C.; Yang, S.L.; Yi, G. Effects of keratinocyte growth factor 2(KGF-2) on keratinocyte growth, migration and on excisional wound healing. Prog. Biochem. Biophys. 2009, 36, 854-862. 